\title{
The Impact Of Macroeconomic Variables On Real Estate Price Forecasting Modelling In Abuja Nigeria
}

\author{
Musa Abubakar Alkali, Ibrahim Atan Bin Sipan, Muhammad Najib Razali
}

\begin{abstract}
This paper examined the impact of macroeconomic variables on real estate price forecasting modelling in Abuja, Nigeria using the family of Box-Jenkins ARIMA models. The ARIMA and ARIMAX models were used to forecast real estate residential price in Abuja, Nigeria using quarterly data from $2000 Q 1$ to $2017 Q$ in Naira (N). The outcome revealed that, macroeconomic variables such as consumer price index, price of crude oil, exchange rate of Naira against US dollar, GDP, interest rate, household income has significant positive impact on the real estate residential price forecasting models of 2 bedroom flat, 3 bedroom flat and 5 bedroom flat, while they have strong negative impact on the price forecasting model of 4 bedroom flat. Moreover, ARIMA and ARIMAX provides best out of sample forecasting models.
\end{abstract}

Index Terms: ARIMA, ARIMAX, Forecasting Models, Macroeconomic Variables.

\section{INTRODUCTION}

Residential real estate market in the past few decades, has witnessed large recurring discrepancies of volumes and prices among many industrialized countries globally [1]. The role of macroeconomic factors on real estate market able to give significant impact to the price condition which evidently can be seen in several countries. For instance the United Kingdom's real estate market in the year 1980, whereas financial liberalization caused a boom in the price, but due to interest rates' increase in the early 1990s, residential real estate prices witnessed a quick decline [2]. Moreover, United States also witnessed real estate prices increase by $61 \%$ between the years of 2000 and 2005 but declined sharply by $38 \%$ in the subsequent four years. Furthermore, other countries like Spain, Ireland and Japan has witnessed similar changes [3].

Macroeconomic variables shows the general movement of the nations' economy. A steady macroeconomic environment will lead to growth of real estate market, however, real estate market varied with other markets [4]. Moreover, the dynamics of real estate market has close relationship with macroeconomic variables and market condition [5]. Several theories confirmed that fluctuations in nation's economy has significance influence on real estate price and has a significant influence on the economy [6].

Revised Manuscript Received on April 19, 2019.

Musa Abubakar Alkali, Faculty of Built Environment and Survey, University Technology Malaysia, Johor, Malaysia.

Ibrahim Atan Bin Sipan, Faculty of Built Environment and Survey, University Technology Malaysia, Johor, Malaysia.

Muhammad Najib Razali, Faculty of Built Environment and Survey, University Technology Malaysia, Johor, Malaysia.
Therefore understanding the effect of macroeconomic variables on real estate price in developing and developed nations is cherished by taking in to consideration, the role of real estate in the global economy. The real estate market is an important element of collective demand in modern economy [7]. Changes in the macro economy can determine the direction of residential price and it has significant policy implications [8] . [9] Revealed that inflation and interest rate has negative impact on real estate prices in China. Moreover, the effect of macroeconomic growth rate on real estate residential prices is progressive. [10] Confirmed that unemployment, GDP, share index, and industrial production were related with residential estate prices in Slovenia, Greece, Poland and Norway. Equally, the instability of real estate price has a great effect on universal economy [11]. However, financial variables might be considered as an appropriate forecaster of economic activities and inflation. Moreover, real estate prices may assist in forecasting inflation and the nations' economic activities [11]. Similarly, more empirical research revealed that changes in real estate price has a significant link with market situations and macroeconomic factors which are predicted to influenced the market supply [12].

Therefore, exploring the role of macro-economic factors is necessary in forecasting and understanding the behavior of real estate market. Nigeria is a country that recently has played an active role in real estate sector which aim to contribute in nations' economic growth. Nigeria, is in the middle of a housing affluent, mainly due to the high demand triggered by increase in population. The housing shortfall is projected around 17 million as at August 2012 (NBS, 2015). Furthermore, Nigeria made intensive effort in improving transparency at real estate market. Solid economic growth and the existence of some of Sub-Saharan Africa's fasted and biggest growing cities of Abuja and Lagos helps to increase the demand for real estate in every sector as Nigeria strengthen its position as a key commercial hub in West Africa. This paper employed times series modelling with a macroeconomic variables to understand the macro-economic impact on real estate price forecasting modelling in Abuja Nigeria. This research was done in line with the studies of [13], [14] and [15] on the impact of macroeconomic factors on real estate price. The research provided a significant

Published By: 
contribution to the current literature by adding knowledge of macroeconomic factors' impact on Abuja residential market and presenting a simple forecasting instrument.

\section{LITERATURE REVIEW}

Forecasting real estate price with Box Jenkins ARIMA modelling technique, uses moving averages, auto regression and a mixture of all. The stages of ARIMA modelling encompasses; pattern recognition, model fitting and forecasting. The ARIMA model is usually identified as BoxJenkins model [16]. Autoregressive integrated moving average model (ARIMA), consist of stable mean and variance [17]. The studies on real estate price forecasting has been carried out by many scholars. The studies shows many types of forecasting classification methods, which comprises univariate and multivariate models, simple and complex model, conventional and advanced models, artificial intelligence and statistical models etc. The autoregressive integrated moving average (ARIMA) models can provide accurate forecasting performance, particularly in the short-term forecasting [18]. ARIMA models provide excellent forecasting capability for short-term forecast [19]. Similarly, ARIMA modelling technique exist in the imperfect character of real estate market which make them to apply the Box-Jenkins method and the problem connected with revolving points identification that can be eliminated with the procedure of moving average [20]. [21] Attempted forecasting Hong Kong real estate price and shows that ARIMA model is capable to signal short-term market trend [18]. $\quad$ Furthermore, [22] forecasted the potential movement of Dubai real estate price through BoxJenkins technique with the monthly values of real estate index. The result affirmed that ARIMA is the appropriate model that described the data better. According to [23] ARIMA is a univariate model that try to portray one variable as autoregressive integrated moving average procedure. The model of ARIMA can be distinguished theoretical, as it disregarded all possible essential hypothesis, excluding those that hypothesize recurring pattern of the variable being studied. In modelling Lithuanian real estate market, [24] revealed that, ARIMA modeling technique is useful method in assessing broad changes in market. He further recommended that Government and central bank can employ ARIMA modelling technique in forecasting real estate price inflation.

Moreover, developers can utilize this technique to make thriving real estate building program. Similarly, investors can integrate ARIMA forecasting model into investment scheme for timing purpose. Real estate price modelling using ARIMA provides in depth for a variety of shareholders. The modelling technique can be used for improvement of monetary policies' oversight, assist in planning for mass housing as a counter cyclical policy and lessen investors risk [24]. More so, according to [25] ARIMA model was invented in 1970s by Box and Jenkins as an effort to explain transformation on the time series using mathematical methods. Occasionally, Box-Jenkins and ARIMA are revealed as equal. ARIMA model was based on amendment of examined values, and its objective is to decrease the difference involving the values produced in the model and the observed ones. However, ARIMAX-
GARCH, ARIMA and ARIMAX models were used to forecast the trends of real estate price index in Canada. The outcome revealed that ARIMA presents best out of sample short term forecasting models [16]. [26] Employed ARIMA modelling to forecast real estate residential prices in UK and discovered that ARIMA model provide short term trend of residential market contrary to multivariate models. Moreover, ARIMA models developed by Box-Jenkins was also used in forecasting real estate price in European countries [27]. Real estate price index was forecasted with ARIMA model by [24] in Lithuania and they confirmed that ARIMA modelling is the best in assessing large price changes in market. The ARIMA model was used to examine the movement of residential estate prices in some countries at Europe [20] which discovered that residential prices' can best be forecasted by ARIMA model. Therefore ARIMA and ARIMAX models were employed to forecast the price changes and determined the influence of macroeconomic variables on real estate price in Abuja, Nigeria.

\section{METHODOLOGY/MATERIALS}

This paper used quarterly data of residential property sales in Abuja and macroeconomic variables such as gross domestic product, consumer price index, interest rate, exchange rate of Naira against US dollar, price of crude oil and household income. The data on real estate prices was obtained from the Nigerian Institution of Estate Surveyors and Valuers Bulletin, while the data on macroeconomic variables was obtained from website of Central Bank of Nigeria $(\mathrm{CBN})$. Due to the non-availability of enough real estate data, the sample of study was restricted to only 4 categories of residential property which includes 2 bedroom, 3 bedroom, 4 bedroom and 5 bedroom flats only. The sample period for real estate and macroeconomic variables data was 2000Q1 - 2017Q4.

To understand the relationship between Abuja residential market and some macroeconomic factors, this study used time series forecasting models with some macroeconomic factors in accordance with previous studies of [13] and [16]. The study used ARIMA (autoregressive integrated moving average) and ARIMAX (autoregressive integrated moving average with exogenous variables) to determine the influence of macroeconomic variables on real estate price in Abuja, Nigeria. Therefore automatic ARIMA forecasting was used with Eviews 9.5, in which the first difference was chosen to make the variables stationery, however max $\mathrm{AR}(4)$ and MA(4) with a forecast length of 16 observations, for 4 years in future (2014-2017) as out of sample. The insample covers 2000Q1 to 2013Q4 with 52 observations.

\section{RESULT AND FINDINGS}

\section{A. ARIMA and ARIMAX forecasting models of 2 bedroom} flat

The ARIMA model was estimated by converting all the variables into $\log$ and also done the first time differencing with forecast length. The outcome shows that 25 ARIMA 
models were estimated and out of 25 models the best model was selected as ARIMA $(4,1,4)$ which has the lowest AIC value of -4.807 . After selecting the best model, the forecasting model of 2 bedroom was developed as shown in Figure 1, where the blue line indicated that the price of 2 bedroom flats in Abuja has dropped gradually compared to the actual price in red line. Which means that real estate investors may not be able to make profit in the future.

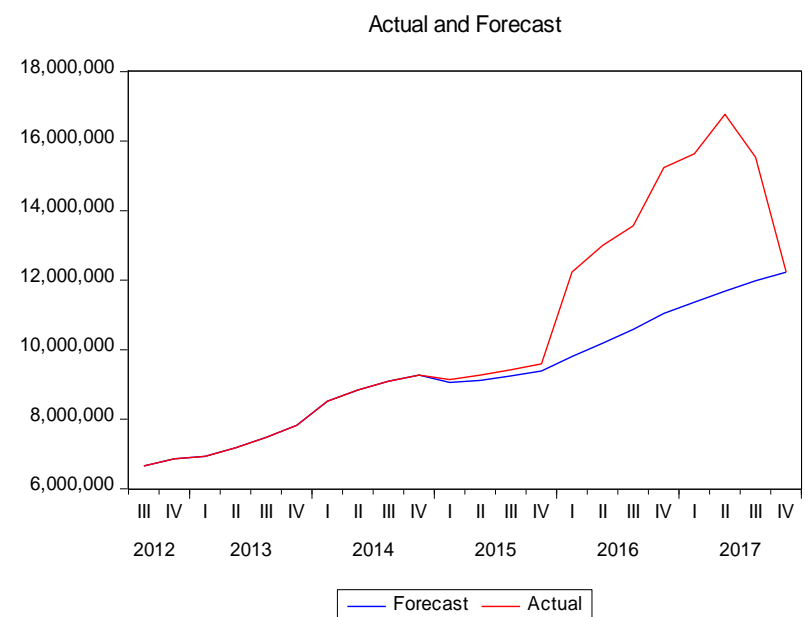

Figure 1 ARIMA forecasting model of 2 bedroom flat Actual and Forecast

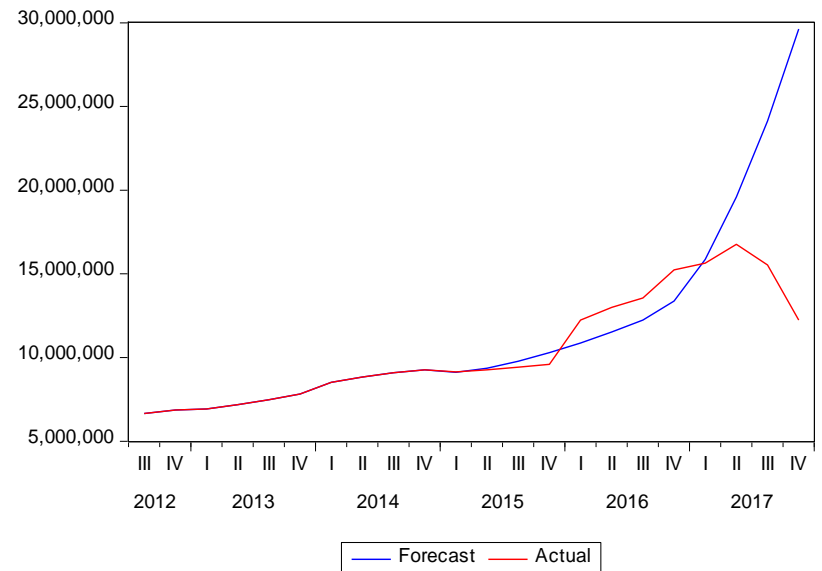

Figure 1 ARIMAX forecasting model of 2 bedroom flat

However, as shown in figure 2, ARIMAX model was estimated again by adding consumer price index (CPI), price of crude oil (COP), Exchange rate, gross domestic product (GDP), household income (HHI) and interest rate (IR) as exogenous variables. The model in Figure 2 shows that, the price of 2 bedroom flats in Abuja will continue to rise according to the ARIMAX model. Which means that real estate investors may enjoy, probably the price of 2 bedroom flats in Abuja will be gradually going up. This shows that macroeconomic variables has strong positive impact on the price of 2 bedroom flats in Abuja, because they influenced the forecasting model compared to the previous forecast without exogenous variables. flat

B. ARIMA and ARIMAX forecasting models of 3 bedroom

The ARIMA model for 3 bedroom flat was estimated by converting all the variables into $\log$ and also done the first time differencing with forecast length 12 . The outcome shows that 25 ARIMA models were estimated and out of 25 models the best model was selected as ARIMA $(4,1,3)$ which has the lowest AIC value of -4.105. After selecting the best model, the price of real estate was forecasted as shown in Figure 3 below which revealed that the price of 3 bedroom flat in Abuja represented by blue line has risen compared with the actual price represented by red line. Which means that real estate investors may be able to make profit in the future.

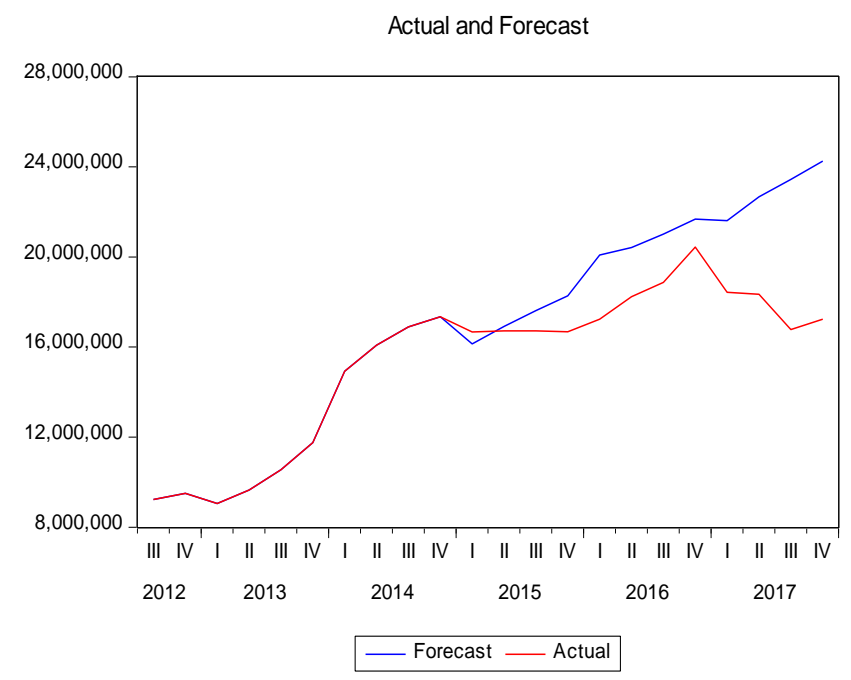

Figure 3 ARIMA forecasting model of 3 bedroom flat Actual and Forecast

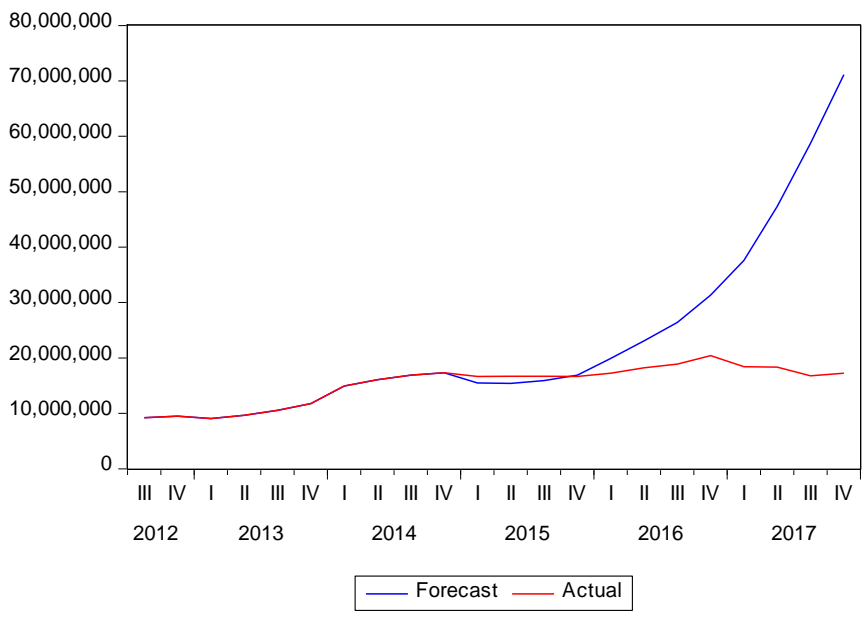

Figure 4 ARIMAX forecasting model of 3 bedroom flat

Similarly, ARIMAX model was estimated again by adding consumer price index (CPI), crude oil price (COP), Exchange rate, gross domestic product (GDP), household income (HHI) and interest rate (IR) as exogenous variables. The model in Figure 4 shows that, the price of 3 bedroom flats in Abuja has risen sharply and it provided a good forecast with highest price increase. This indicated that real estate investors may enjoy, probably the price of 3 bedroom flats in Abuja will continue to rise in the future. This revealed that macroeconomic variables has strong positive impact on the price of 3 bedroom flats in Abuja because they influenced the forecasting price compared to the

Published By: 
previous forecast without exogenous variables.

\section{ARIMA and ARIMAX forecasting models of 4 bedroom} flat

The ARIMA model automatically, by converting all the variables into $\log$ and also done the first time differencing with forecast length 12 . The outcome shows that 25 ARIMA models were estimated and out of 25 models the best model was selected as ARIMA $(1,1,4)$ which has the lowest AIC value of -3.525 . Therefore, after selecting the best model, the price of 4 bedroom was forecasted as shown in Figure 5 which indicated that the price of 4 bedroom flat represented with blue line has risen higher than the actual price represented with red line. This indicated means that real estate investors may be able to make profit in the future.

Actual and Forecast

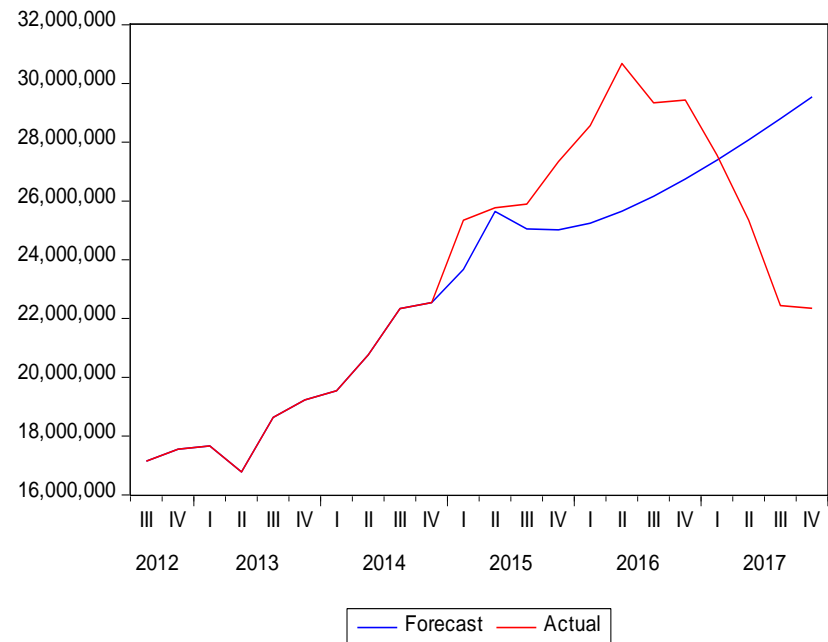

Figure 5 ARIMA forecasting model of 4 bedroom flat Actual and Forecast

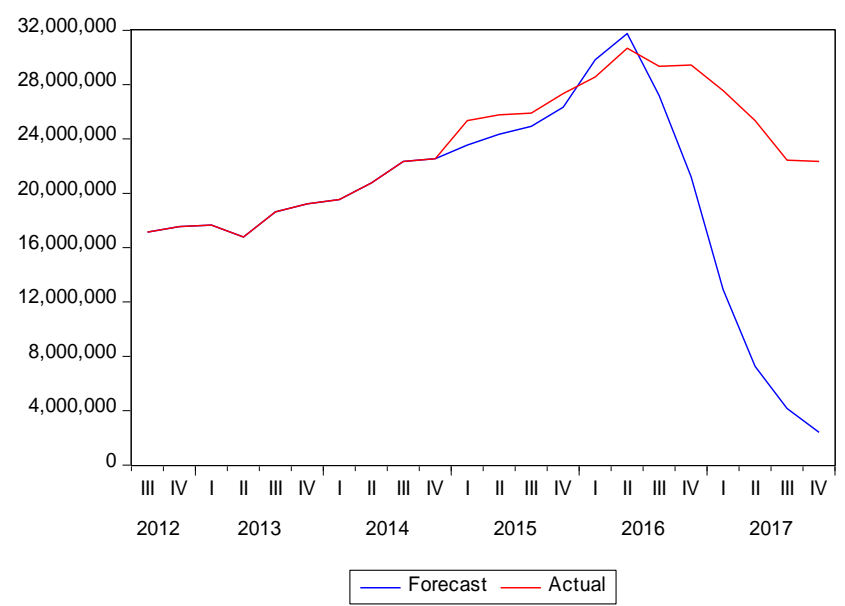

Figure 6 ARIMAX forecasting model of 4 bedroom flat

However, ARIMAX model was estimated again by adding consumer price index (CPI), crude oil price (COP), Exchange rate, gross domestic product (GDP), household income (HHI) and interest rate (IR) as exogenous variables. The model in Figure 6 shows that, the price of 4 bedroom flats has fallen sharply compared to the actual price. This indicated that real estate investors may not be able to make profit, probably the price of 4 bedroom flats in Abuja will continue to fall in the future. This shows that macroeconomic variables has strong negative impact on the price of 4 bedroom flats in Abuja because they influenced the forecasting price compared to the previous forecast without exogenous variables.

\section{ARIMA and ARIMAX forecasting models of 5 bedroom} flat

ARIMA model was estimated automatically by converting all the variables into log and also done the first time differencing with forecast length 12 . The outcome shows that 25 ARIMA models were estimated and out of 25 models the best model was chosen as ARIMA $(4,1,3)$ which has the lowest AIC value of -4.590. After selecting the best model, the price of 5 bedroom was forecasted as shown in Figure 7, which indicated that, the price of 5 bedroom flat in Abuja is moving gradually with the actual price according to the ARIMA model. Which means that real estate investors may be able to make profit in the future. Actual and Forecast

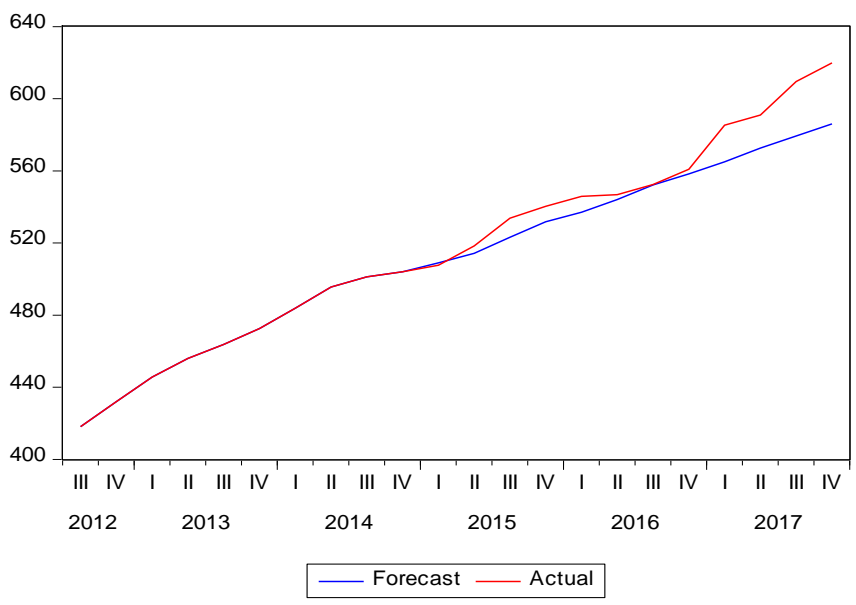

Figure 7 ARIMA forecasting model of 4 bedroom flat Actual and Forecast

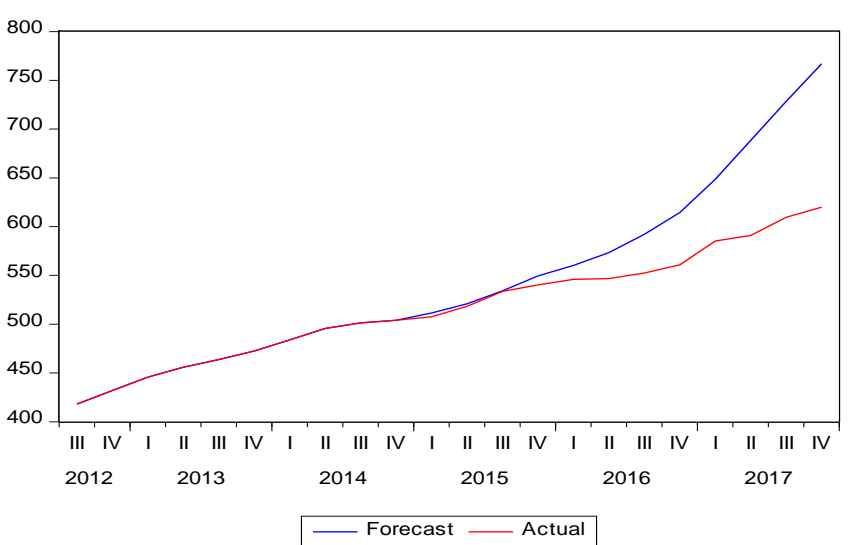

Figure 8 ARIMA forecasting model of 4 bedroom flat

However, ARIMAX model was estimated again by adding consumer price index (CPI), crude oil price (COP), Exchange rate, gross domestic product (GDP), household income (HHI) and interest rate (IR) as exogenous variables. The model in Figure 4.8 shows that, the price of 5 bedroom flats in Abuja will continue to rise according to the ARIMAX model. Which means that real estate investors

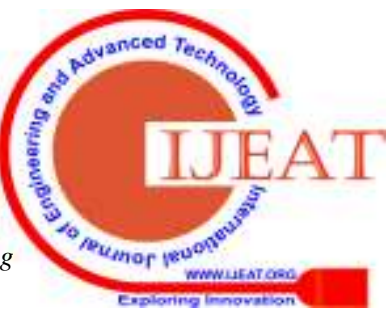


may enjoy, probably the price of 5 bedroom flats in Abuja will go higher. This shows that macroeconomic variables has strong positive impact on the price of 3 bedroom flats in Abuja, because they influenced the forecasting price compared to the previous forecast without exogenous variables.

The outcome of the research confirmed the findings of (16) that ARIMAX model performance revealed that macroeconomic variables has great influence in the future development of property market, because they improve the performance of real estate forecasting. It was also confirmed that ARIMAX model, with macroeconomic variables presents best out of sample forecasting models.

\section{CONCLUSION}

The paper presented the outcome of the impact of macroeconomic variables on residential price in Abuja, Nigeria. The result shows that macroeconomic variables has strong impact on the residential price in Abuja. Furthermore, the results shows that macroeconomic variables plays a significant part in developing the real estate price forecasting models. The macroeconomic variables has a strong influence on real estate price forecasting models and this provide a good information to the government and real estate investors as well.

The paper also revealed that the ARIMA and ARIMAX presents a good out of sample forecasting models for real estate residential property price in Abuja. The results confirmed the findings of [16] that macroeconomic variables definitely improves the performance of the real estate forecasting models. Moreover, the ARIMAX model performance also revealed that macroeconomic variables contain high information content concerning future development of real estate market in Abuja Nigeria. The paper also affirmed the findings of [18] that prediction of a single residential price changes is difficult but aggregate real estate price changes can be forecasted. The limitation of this research is that, there is limited data of all categories of residential price in Abuja. Moreover, it is difficult to get the data of more macroeconomic variables. The future research can be extended to include more categories of residential real estate such as, (Detached, Semi-Detached and Terrace). Similarly the future research can add many macroeconomic variables as explanatory variables. The research covered only federal capital territory Abuja, therefore future research should covered more cities in Nigeria, more importantly Kano and Lagos.

\section{ACKNOWLEDGMENT}

This research significantly acknowledge the grant provided by International Doctorate Fellowship by University of Technology Malaysia. The financial support provided by Tertiary Education Trust Fund supported by the Nigerian government was also acknowledge.

\section{REFERENCES}

1. Nneji O, Brooks C, Ward CWR. House price dynamics and their reaction to macroeconomic changes. Econ Model. 2013;32(1):172-8.

2. Begiazi K, Asteriou D, Pilbeam K. A multivariate analysis of United States and global real estate investment trusts. Int Econ Econ Policy. 2016;13(3):46782.

3. Jones C, Richardson HW. Housing markets and policy in the UK and the USA: A review of the differential impact of the global housing crisis. Int J Hous Mark Anal. 2014;7(1):129-44.

4. Ong TS. Factors Affecting the Price of Housing in Malaysia. J Emerg Issues Econ Financ Bank 2013;1(5):414-29.

5. Guerrieri V, Hartley D, Hurst E. Endogenous Gentrification and Housing-Price Dynamics. 2010;(No. 10-08):1-40.

6. Ali Akbar Naji Meidani, Maryam Zabihi MA. House prices, Economic Output, and Inflation Interactions in Iran. Res Appl Econ. 2011;Vol. 3, 2015.

7. Whelan S. Housing Markets and Macroeconomic Policy [Internet]. Vol. 3, International Encyclopedia of Housing and Home. Elsevier Ltd.; 2012. 523-527 p.5

8. Duan K, Mishra T, Parhi M. Space matters: Understanding the real effects of macroeconomic variations in cross-country housing price movements. Econ Lett [Internet]. 2018;163:130-5.

9. Zhang H, Li L, Hui ECM, Li V. Comparisons of the relations between housing prices and the macroeconomy in China's first-, second- and third-tier cities. Habitat Int [Internet]. 2016;57:24-42.

10. Grum B, Govekar DK. Influence of Macroeconomic Factors on Prices of Real Estate in Various Cultural Environments: Case of Slovenia, Greece, France, Poland and Norway. Procedia Econ Finance. (2015):597-604.

11. Ghorbani S. Forecasting the House Price for Ahvaz City?: the Comparison of the Hedonic and Artificial Neural Network Models. Urban Econ Manag. 2017;5(19):29-45.

12. Ciarlone A. House price cycles in emerging economies. Stud Econ Financ [Internet]. 2015;32(1):17-52.

13. Brooks C, Tsolacos S. Forecasting real estate returns using financial spreads. J Prop Res. 2001;18(3):235-48.

14. Karakozova O. Modelling and forecasting office returns in the Helsinki area. J Prop Res. 2004;21(1):51-73.

15. Vishwakarma VK. Forecasting Real Estate Business?: Glob J Bus Res. 2013;7(3):1-14.

16. Moosazadeh M, Nasehi M, Bahrampour A, Khanjani N, Sharafi S, Ahmadi S. Forecasting Tuberculosis Incidence in Iran Using Box-Jenkins Models. 2014;16(5).

17. Crawford GW, Fratantoni MC. R EAL E STATE Assessing the Forecasting Performance of RegimeSwitching, ARIMA and GARCH. Real Estate Econ. 2003;31(2):223-43.

18. Tan $\mathrm{Y}, \mathrm{Xu} \mathrm{H}$, Hui ECM. Forecasting property price indices in Hong Kong based on grey models. Int J Strateg Prop Manag. 2017;21(3):256-72.

19. Stevenson S. A comparison of the forecasting ability of ARIMA models. J Prop Invest Finance. 2007;25(3):22340.

20. Boitan IA. Residential property prices' modeling: evidence from selected European countries. J Eur Real Estate Res . 2016;9(3):273-85.

21. Tse RYC. An Application of the ARIMA Model to RealEstate Prices in Hong Kong. J Prop Finance.

22. Hepsen A, Vatansever M. Forecasting future trends in Dubai housing market by using Box-Jenkins autoregressive integrated moving average. Int $\mathrm{J}$ Hous Mark Anal. 2011;4(3):210-23.

23. Stevenson S, Young J. Forecasting Housing Supply? Empirical Evidence from the Irish Market Forecasting Housing Supply?: Empirical Evidence from the Irish Market. 2007;:37-41. 
24. Huston AJ and S. ARIMA modelling of Lithuanian house price index. Int J Hous Mark Anal. 2015;8(1):13547.

25. Sato RC. Disease management with ARIMA model in time series. Rev Basic Sci. 2013;11(12):128-31.

26. Marwani HAA-. An Approach to Modeling and Forecasting Real Estate Residential Property Market. 2014;

27. Dejniak D,. Application of Arima Models in Real Estate Market Forecasting. Conf Proc. 2017;117-25.

\section{AUTHORS PROFILE}

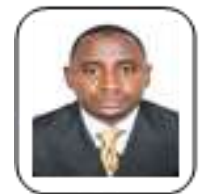

Musa Abubakar Alkali was born on 18th September 1978 at Dukku Local Government Area, Gombe State Nigeria. He obtained B-Tech Estate Management from Abubakar Tafawa Balewa Univerity Bauchi, Nigeria in 2005, MSc Real Estate and Facilities Management at University Tun Hussein Onn Malaysia in 2015 and PhD Real Estate (In View). Presently the author is lecturer at the Department of Estate Management, Bayero University Kano Nigeria. He authored many publications in conference proceedings and journal papers.

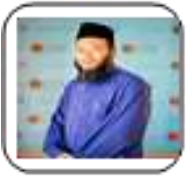

Ibrahim @ Atan Sipan is a Senior Lecturer at the Faculty of Geoinformation and Real Estate, Universiti Teknologi Malaysia, Johor Bahru. He holds a Bachelor Degree in Property Management, Master in Property Business, and Doctor of Philosophy in Real Estate. He specializes in real estate analyses especially valuation, mass appraisal and GIS. He worked for ten years in the Department of Valuation and Property Services Malaysia before joining Universiti Teknologi Malaysia in 1990. Since then, he has been involved in a number of GIS and real estate related research and consultancy work for the past 10 years.

Muhammad Najib Razali. Faculty of Built Environment and Survey, University Technology Malaysia, Johor, Malaysia. 